Europe's Journal of Psychology, 7(1), pp. 1-7

www.ejop.org

\title{
Evidence-based ethical problem solving to guide practise in psychology research
}

\author{
By Vania Ranjbar
}

The University of Edinburgh

\section{Introduction}

Looking back to the World War II activities, undertaken in the name of research, there is little room for doubt as to why we have Ethics Committees (ECs; or Institutional Review Boards, IRBs, as they are referred to in the U.S.) and various ethical codes of conduct. On one hand, no contemporary scientist would deny the need for a peer review process to ensure ethical treatment and protection of human research subjects, especially in psychology research. On the other hand, anecdotal evidence of ECs becoming an impediment to scientists and their research is mounting up (Ceci \& Bruck, 2009; Fiske, 2009; Sieber, 2009; Tully, Ninis, Booy, \& Viner, 2000); albeit empirical data on the issue is lacking (Ceci \& Bruck, 2009; Fiske, 2009). There appears, however, to be a general sense in the academic world that this impediment sometimes arises as a result of EC members' lack of awareness or understanding of the particular research topic under review and its associated literature and methodologies, including what may constitute contemporary best practise in the area. This may then give rise to competing ethical concerns, between EC members and their department colleagues. Members of psychology ECs are not, and could not possibly be, experts on all psychological topics and methodologies. Scientists, however, have an "ethical responsibility not to prevent research that might improve the human condition" (Fiske, 2009, p. 30) and thus potentially important research ought not to be prevented simply due to a lack of awareness amongst ECs. Fiske (2009) argues how the responsibilities of ECs can be theorised in terms of prevention and promotion: preventing negative outcomes of research participation, while promoting beneficial research. The aim of this editorial is thus to encourage psychology students (and non-students) to start collecting data on the experiences of research participation to, first, contribute to a knowledge base that can be used 
to facilitate ECs' decision-making, especially when concerning sensitive research; and, second, to help ECs to achieve both goals of prevention and promotion. Furthermore, such data collection would not only facilitate ECs to achieve their goals but it could potentially be valuable in evaluating whether ECs do in fact achieve their goals. The aim of this brief editorial is thus to encourage more engagement in Evidence-Based Ethical Problem Solving (Sieber, 2009).

\section{Reactions to Research Participation in Sensitive Research: Presumptions Versus Empirical Evidence}

Ethical dilemmas are particularly pertinent within the social sciences, and even more so when conducting sensitive research; that is, "research which potentially poses a substantial threat to those who are or have been involved in it" because the topics are considered to be "private, stressful or sacred" and thus pose an "intrusive threat" (Lee, 1993, p. 4). Lee, however, further points out that "the sensitive character of a piece of research seemingly inheres less in the specific topic and more in the relationship between that topic and the social context" (Lee, 1993, p. 5). In an academic context it is the issue of responsibility, I would like to argue, that becomes central. With vulnerable samples there is an underlying fear that participating in research that addresses their negative experiences might exacerbate their distress and thus have harmful consequences. It is, arguably, the responsibility that scientists need to take for this potential outcome that brands this kind of research as "sensitive research". If one, then, (inaccurately) presumes that exacerbated distress is an inevitable outcome of sensitive research, then this type of potentially important research might be more at risk of being delayed, rejected, or modified in such ways that the results are altered (Goodyear-Smith, Lobb, Davies, Nachson, \& Seelau, 2002). There is thus the risk that unfounded presumptions may prevent potentially important research.

The empirical evidence, however, speaks differently. First, although most likely there will always be a subset of a sample that will report negative research experiences to varying extents when participating in sensitive research, a majority of research participants tend to report being pleased to have participated in such studies and report no elevated distress due to their participation (Priebe, 2009; Scott, Valery, Boyle, \& Bain, 2002). This seems to be the case even in research as sensitive as asking adolescents about sexual abuse, where the majority disagreed with statements such as "the questions were unpleasant to answer" or "one should not ask people such questions" (Priebe, 2009). Even amongst the adolescents who did report experiences of sexual abuse did the majority disagree with such statements. Systematically 
assessing research participation can thus provide us with empirical evidence which highlights discrepancies between inaccurate presumptions and real life situations.

Second, despite this risk of exacerbated distress and negative outcomes, scientists, and participants alike, are increasingly recognising the benefits of participation in sensitive research (Kelly \& Halford, 2007). For example, in a study with female survivors of interpersonal violence (Griffin, Resick, Waldrop, \& Mechanic, 2003), not only was participation found not to have any harmful psychological effects but it was in actual fact perceived as a positive and beneficial experience despite participants having experienced strong emotions during the assessments. During my own current PhD research on the experience of AIDS-related bereavement, aid workers predominantly report their participation in the qualitative interviews in a positive light. As one participant put it, "I've counselled myself". This is not to say that research participation ought to be erroneously advertised as an opportunity for counselling or other psychological interventions, unless it is specifically clinical research conducted for that purpose and with qualified practitioners. It is important to highlight this distinction to participants as to prevent any false expectations. Despite participants explicitly being informed about this distinction, participation may nonetheless come to resemble an informal "counselling" opportunity for some as it provides an opportunity to reflect. Benefits from participation in trauma research are thought to result from reflection on one's experiences, which in turn can lead to new insights (Newman \& Kaloupek, 2004).

In my previous (qualitative) research on recovery from sexual abuse, when asked to freely comment on their experience of participation, over one third of the sample explicitly stated having felt good about participating. Furthermore, the majority of the sample reported having partaken in the study hoping that their participation would contribute to improved situations for other survivors. Participants had previously described how being able to appreciate the good aspects of life, despite their traumas, was important to their recovery process; participating in research with the aspiration to improve the situation for other survivors enabled them to focus on the good in life to overcome the bad (the aftermath of trauma). This finding is in line with other studies that show that individuals participating in trauma research often do so to help others (e.g., Campbell \& Adams, 2009). We must not, after all, forget that the conception of and advances in research on sexual and domestic violence originated partly in the focus groups held by feminist organisations with women who spoke out about their own experiences - and were relieved about doing so (Jones \& Cook, 2008). 
It is thus clear that the actual experiences and perceptions of trauma research participants, based on empirical evidence, can noticeably differ from presumptions regarding such experiences, based on myths and stereotypes of trauma survivors. Consequently, empirical investigations on the matter are important to identify and highlight any such discrepancies.

\section{The Reactions to Research Participation Questionnaire (RRPQ)}

One effective tool for collecting such empirical evidence and for assessing the experience of research participation is the Reactions to Research Participation Questionnaire (RRPQ; Newman, Willard, Sinclair, \& Kaloupek, 2001). Research participation can be theorised within a cost-benefit framework: participation is more likely if the benefits are greater than the costs (Campbell \& Adams, 2009; Newman, et al., 2001). The RRPQ is a quantitative measure that assesses participants' experiences of the research procedures and their perceptions of the costs and benefits of participation across five factors: Participation, Personal Benefits, Emotional Reactions, Perceived Drawbacks, and Global Evaluation. Participants are asked to indicate on a 5-point Likert scale the extent to which they agree or disagree with 23 items dealing with their experience of participating in the study, such as, "Knowing what I know now, I would participate in this study if given the opportunity" and "The research raised emotional issues for me that I had not expected". It has previously been successfully utilised in studies of domestic violence (Johnson \& Benight, 2003), with children (Chu, DePrince, \& Weinzierl, 2008; KassamAdams \& Newman, 2002; RRPQ-C), with cancer patients (Whitaker, Brewin, \& Watson, 2008), and samples vulnerable in other ways (Widom \& Czaja, 2005). In addition to assessing participants' reactions to participation, the RRPQ also allows individuals to report on their reasons for participating. As such, using the RRPQ, either in full or by selecting appropriate individual items from the scale, enables psychology researchers to collect necessary empirical evidence to contribute to ethical advancements within the discipline.

\section{Summary}

Conclusively, there are three main arguments for including assessments of reactions to research participation in psychology studies. First, if ECs wrongly hold the view that researching certain topics or adopting certain methodologies may be harmful to participants, then this can cause delays in research being conducted, contribute to a waste of resources, inconsistencies across ECs, and in some cases even prevent potentially important research from being conducted (Ceci, Peters, \& Plotkin, 1985; 
Ceci \& Bruck, 2009; Goldman \& Katz, 1982; Middle, Johnson, Petty, Sims, \& Macfarlane, 1995; Walsh, 1998). It is, therefore, important that psychology researchers collect empirical evidence to help ECs and peers make the best possible decisions that are guided by this evidence rather than by presumptions that are based on personal opinions or myths and that may be inaccurate. Data collection on reactions to research participation could thus contribute to ECs achieving their promotion objective.

Second, Ceci and Bruck (2009) raise the issue that ECs were established with the remit to protect research participants by ensuring ethical treatment, but that evidence that this objective is being achieved is lacking. Empirical evidence on research participants' experiences across various methodologies could enable a comparison of these methodologies to help identify those most suitable with regard to ethical conduct. Data collection on reactions to research participation could thus contribute to ECs achieving their prevention objective.

Finally, as the RRPQ also asks about individuals' reasons for participating in the research, in addition to learning more about the experience of participating in (sensitive) research, we can also learn about why people participate in our research studies. This piece of knowledge may help us learn about any peculiarities of our sample, which may be useful to consider when drawing conclusions about our data. Data collection on reactions to research participation could thus potentially contribute to better understanding of findings.

Based on these arguments I would urge psychology students and other researchers, especially those conducting sensitive research, to consider incorporating assessments of reactions to research participation into their studies.

\section{Acknowledgements}

The RRPQ was developed by Elana Newman, at the University of Tulsa, and her colleagues. It is available, for free, on her personal website.

\section{References}

Campbell, R., \& Adams, A. E. (2009). Why do rape survivors volunteer for face-to-face interviews? A meta-study of victims' reasons for and concerns about research participation. Journal of Interpersonal Violence, 24(3), 395-405. 
Ceci, S., Peters, D., \& Plotkin, J. (1985). Human subjects review, personal values, and the regulation of social science research. American Psychologist, 40 (9), 994-1002.

Ceci, S. J., \& Bruck, M. (2009). Do IRBs pass the minimal harm test? Perspectives on Psychological Science, 4 (1), 28-29.

Chu, A. T., DePrince, A. P., \& Weinzierl, K. M. (2008). Children's perceptions of research participation: examining trauma exposure and distress. Journal of Empirical Research on Human Research Ethics, 3(1), 49-58.

Fiske, S. T. (2009). Institutional Review Boards: From bane to benefit. Perspectives on Psychological Science, 4 (1), 30-31.

Goldman, J., \& Katz, M. D. (1982). Inconsistency and Institutional Review Boards. The Journal of the American Medical Association, 248(2), 197-202.

Goodyear-Smith, F., Lobb, B., Davies, G., Nachson, I., \& Seelau, S. (2002). International variation in ethics committee requirements: comparisons across five Westernised nations. BMC Medical Ethics, 3(1), 2-9.

Griffin, M. G., Resick, P. A., Waldrop, A. E., \& Mechanic, M. B. (2003). Participation in trauma research: is there evidence of harm? Journal of Traumatic Stress, 16(3), 221-227.

Johnson, L. E., \& Benight, C. C. (2003). Effects of trauma-focused research on recent domestic violence survivors. Journal of Traumatic Stress, 16(6), 567-571.

Jones, H., \& Cook, K. (2008). Rape Crisis: Responding to sexual violence. Lyme Regis: Russell House.

Kassam-Adams, N., \& Newman, E. (2002). The reactions to research participation questionnaires for children and for parents (RRPQ-C and RRPQ-P). General Hospital Psychiatry, 24 (5), 336-342.

Kelly, A. B., \& Halford, W. K. (2007). Responses to ethical challenges in conducting research with Australian adolescents. Australian Journal of Psychology, 59(1), 24-33.

Lee, R. M. (1993). Doing research on sensitive topics. London: SAGE.

Middle, C., Johnson, A., Petty, T., Sims, L., \& Macfarlane, A. (1995). Ethics approval for a national postal survey: recent experience. BMJ, 311 (7006), 659-660.

Newman, E., \& Kaloupek, D. G. (2004). The risks and benefits of participating in traumafocused research studies. Journal of Traumatic Stress, 17(5), 383-394. 
Newman, E., Willard, T., Sinclair, R., \& Kaloupek, D. (2001). Empirically supported ethical research practice: the costs and benefits of research from the participants' view. Accountability in Research: Policies and Quality Assurance, 8(4), 309-329.

Priebe, G. (2009). Adolescents' experiences of sexual abuse. Prevalence, abuse characteristics, disclosure, health and ethical aspects. Lund: Lund University.

Scott, D. A., Valery, P. C., Boyle, F. M., \& Bain, C. J. (2002). Does research into sensitive areas do harm? Experiences of research participation after a child's diagnosis with Ewing's sarcoma. Medical Journal of Australia, 177(9), 507-510.

Sieber, J. E. (2009). Evidence-Based Ethical Problem Solving (EBEPS). Perspectives on Psychological Science, 4 (1), 26-27.

Tully, J., Ninis, N., Booys, R., \& Viner, R. (2000). The new system of review by multicentre research ethics committees: prospective study. BMJ, 320 (7243), 1179-1182.

Walsh, K. (1998, November). Researching the sensitive: gendered violence and child abuse. Paper presented at the Australian Association for Research in Education Annual Conference, Adelaide, Australia.

Whitaker, K. L., Brewin, C. R., \& Watson, M. (2008). Intrusive cognitions and anxiety in cancer patients. Journal of Psychosomatic Research, 64 (5), 509-517.

Widom, C. S., \& Czaja, S. J. (2005). Reactions to research participation in vulnerable subgroups. Accountability in Research: Policies \& Quality Assurance, 12 (2), 115-138.

\section{About the author:}

Vania Ranjbar is currently a PhD psychology student at the University of Edinburgh. Her research area of interest is psychological trauma. She has previously conducted work on recovery from sexual abuse and is a member of the British Psychological Society Scotland Survivors of childhood sexual abuse working party (BPSSS), the UK Psychological Trauma Society (UKPTS), and the European Society for Traumatic Stress Studies (ESTSS). Currently she is investigating the traumatic effects of bereavement due to HIV/AIDS and tuberculosis on aid workers in South Africa.

Address for correspondence: Vania Ranjbar, Psychology, The University of Edinburgh, 57 George Square, Edinburgh, EH8 9JU, UK

E-mail: V.Ranjbar@sms.ed.ac.uk 